\title{
Bopyrid isopods do not castrate the simultaneously hermaphroditic shrimp Lysmata amboinensis (Decapoda: Hippolytidae)
}

\author{
Ricardo Calado $^{1,2, *}$, António Vitorino ${ }^{2,3}$, Maria Teresa Dinis ${ }^{1}$ \\ ${ }^{1}$ CCMAR Universidade do Algarve, Campus de Gambelas, 8000-117 Faro, Portugal \\ ${ }^{2}$ Templo Aquático, Rua de Santa Marta No. 27, 1150-291 Lisboa, Portugal \\ ${ }^{3}$ Universidade Lusófona, Departamento de Ciências Naturais e Biológicas, Campo Grande, 376-1749 Lisboa, Portugal
}

\begin{abstract}
This study evaluates possible parasitic castration induced by a bopyrid isopod of the genus Parabopyrella, which parasitizes the branchial chamber of the simultaneously hermaphroditic shrimp Lysmata amboinensis. Parasitized shrimp (PS) carried embryos and produced significantly fewer larvae (mean \pm SD: $363 \pm 102 ; p=0.002)$ than formerly parasitized shrimp (FPS) $(1297 \pm 143)$ and unparasitized shrimp (US) paired with other US (1409 \pm 102$)$, with PS (1362 \pm 234$)$ or with FPS $(1384 \pm 157)$. Starvation trials revealed no significant differences in the quality of larvae produced by PS, FPS and US paired with other US, PS and FPS. Host embryo production is only quantitatively, not qualitatively, affected, probably due to nutritional drain and/or endocrine disruption caused by the parasite. The host male sexual system remains fully functional and 'reproductive death' does not occur. The feminization of pleopods that prevents parasitized males of gonochoric species from successfully copulating seems to have no effect on $L$. seticaudata: pleopods are always feminized during their transition from male to simultaneous hermaphrodite phase, with adults being able to successfully fertilize broods. Parabopyrella sp. significantly affects the female sexual system of its host, but does not cause castration, as recorded for L. seticaudata parasitized by the bopyrid isopod Eophryxus lysmatae (an abdominal parasite).
\end{abstract}

KEY WORDS: Parabopyrella $\cdot$ Bopyrid isopods · Parasitic castration · Simultaneous hermaphroditism · Lysmata amboinensis

Resale or republication not permitted without written consent of the publisher

\section{INTRODUCTION}

Bopyrid isopods are holoparasites, having decapod crustaceans as their definitive hosts (Markham 1986). The life history of bopyrid isopods can be briefly described by the existence of a free swimming epicaridean larva that attaches itself to a calanoid copepod, which acts as an intermediate host. The larva metamorphoses into a microniscus (Dale \& Anderson 1982), which remains on the host copepod until metamorphosing into a free swimming cryptoniscus larva. The cryptoniscus eventually leaves the copepod, becoming the infective stage of the definitive host. The first cryptoniscus settling on a decapod (final host) metamorphoses into a female while future cryptonisci settling on the same host metamorphose into males (O'Brien \& Van Wyk 1985) Typically, a final host will have a single female bopyrid in the branchial chamber or clinging to its abdomen accompanied by 1 or 2 dwarf males (Anderson 1990).

Bopyrids cause the parasitic castration of their hosts, which involves 2 associated but perhaps distinct phenomena: gonads of a female host do not mature and parasitized males are feminized (O'Brien \& Van Wyk 1985). Host reproductive potential is always substantially reduced, and infection generally causes 'reproductive death' (Van Wyk 1982). 
Previous research addressing parasitic castration among decapods has mainly focused on gonochoric species. However, hippolytid shrimp of the genus Lysmata display a sexual system unique among decapod crustaceans - protandric simultaneous hermaphroditism (Bauer 2000). Calado et al. (2005) demonstrated that the bopyrid isopod Eophryxus lysmatae (Caroli, 1930), an abdominal parasite, caused parasitic castration of the female function of the simultaneous hermaphrodite Lysmata seticaudata (Risso, 1816). Nevertheless, parasitized hosts could still successfully act as males and fertilize egg clutches. So far, no study has addressed the effect of branchial bopyrid isopods on the reproductive performance of simultaneously hermaphroditic shrimp.

The present study evaluated the existence of parasitic castration induced by a bopyrid isopod from the genus Parabopyrella Markham, 1985, a member of the subfamily Bopyrinae, which parasitizes the branchial chamber of the simultaneously hermaphroditic shrimp Lysmata amboinensis.

\section{MATERIALS AND METHODS}

Lysmata amboinensis in simultaneously hermaphroditic reproductive phase were imported from the Philippines and separated in 3 groups: unparasitized shrimp (US) ( $\mathrm{n}=10)$, shrimp carrying a bopyrid isopod in the branchial chamber (PS) $(n=5)$ and shrimp bearing a bulge in the branchiostegite owing to the former presence of a bopyrid isopod (FPS) $(n=5)$. PS and FPS were paired with US shrimp of similar total length (distance between the anterior end of the rostrum and posterior edge of the telson) $(55 \pm 2 \mathrm{~mm})$. A total of 5 shrimp pairs were used in each trial. All US previously used in Trials 1 and 2 were grouped in 5 random pairs to ascertain their ability to fertilize and spawn eggs. Shrimp were kept in 301 aquariums equipped with a larval collector (mesh size $500 \mu \mathrm{m}$ ) at $26^{\circ} \mathrm{C}$, $35 \%$ salinity, and with a photoperiod of 12:12 h light:dark. Artificial seawater was prepared using freshwater purified by a reverse osmosis unit and mixed with the salt Crystal Sea produced by Marine Enterprises International. Shrimp were fed ad lib. 4 times per day with Marine Cuisine, a frozen food for marine aquarium organisms manufactured by San Francisco Bay Brand.

After performing reproductive trials, PS and FPS were stored in ethanol for morphological observation and future diagnosis of the parasitic bopyrid isopod species (work in progress).

Because Lysmata amboinensis is not able to selffertilize or store sperm for later egg fecundation (the eggs extruded by unpaired shrimp always abort after a few days), the reproductive performance of each shrimp was evaluated by counting the number of hatched larvae from the first 3 embryo batches produced after pairing. In order to evaluate larval quality, 15 larvae per batch of each PS and FPS were randomly selected and placed in starvation in small plastic containers (20 ml volume). The same procedure was applied to larvae produced by US paired with US, PS and FPS. Larval survival was checked 24, 48, 72, 96 and $120 \mathrm{~h}$ after hatching, with the water from each container being renewed daily. The molts of all tested shrimp were collected for morphological comparison.

The number of produced larvae and larval survival of US, PS and FPS was compared using 1-way ANOVA after checking assumptions. Results were considered statistically significant at the 0.05 probability level (Zar 1996).

\section{RESULTS}

Of infected or previously infected shrimp, $40 \%$ of PS and $60 \%$ of FPS carried (or used to carry) the bopyrid isopod on the left side of the cephalothorax (dorsal view). Apart from bearing a bulge in the area occupied (or formerly occupied) by the bopyrid parasite, PS and FPS did not display any other morphological differences when compared with US.

PS carried embryos (Fig. 1) and produced significantly fewer larvae (mean \pm SD: $363 \pm 102 ; \mathrm{p}=0.002$ ) than FPS $(1297 \pm 143)$ and US paired with other US $(1409 \pm 102)$, PS $(1362 \pm 234)$ and FPS $(1384 \pm 157)$. There were no significant differences among the number of larvae produced by FPS and US paired with other US, PS and FPS ( $p=0.34)$.

Starvation trials revealed no significant differences in the quality of larvae produced by PS, FPS and US paired with other US, PS and FPS and starved for the same period of time (24, 48, 72, 96 and 120 h) (Fig. 2).

The parasitic isopod Parabopyrella sp. did not synchronize its molt with that of its host, molting during the 7th to 9th day of the intermolt period of their host. All parasitic isopods successfully incubated embryos and released larvae during the experimental trials.

Two PS lost their parasites after the experimental trial, and after only 15 to $20 \mathrm{~d}$ started to produce similar (1207 $\pm 253 ; \mathrm{p}=0.25$ ) larval batches to those recorded for US and FPS. No US or FPS became infected by bopyrid isopods during the reproductive trials.

\section{DISCUSSION}

The present study shows that the bopyrid isopod Parabopyrella sp. (a branchial parasite) significantly affects the female sexual system of its host, the simultane- 


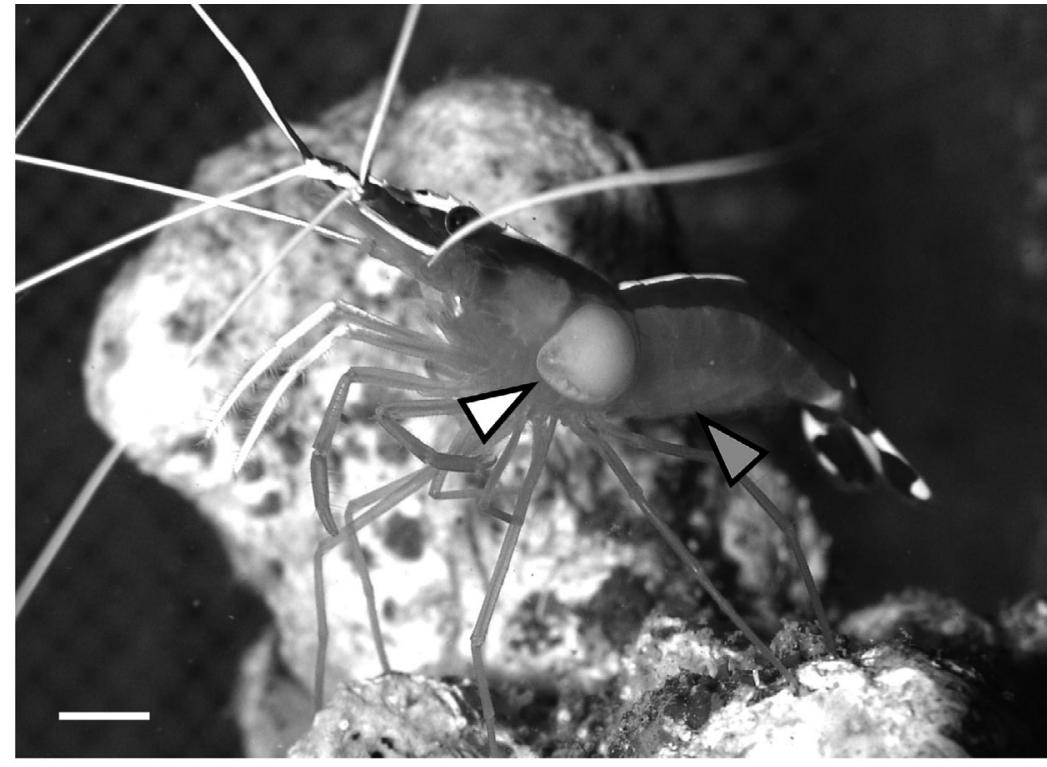

Fig. 1. Lysmata amboinensis. Simultaneously hermaphroditic shrimp parasitized by the bopyrid isopod Parabopyrella sp. on the left side of the cephalothorax (white arrow) and carrying fertilized embryos attached to the pleopods (grey arrow). Scale bar $=10 \mathrm{~mm}$

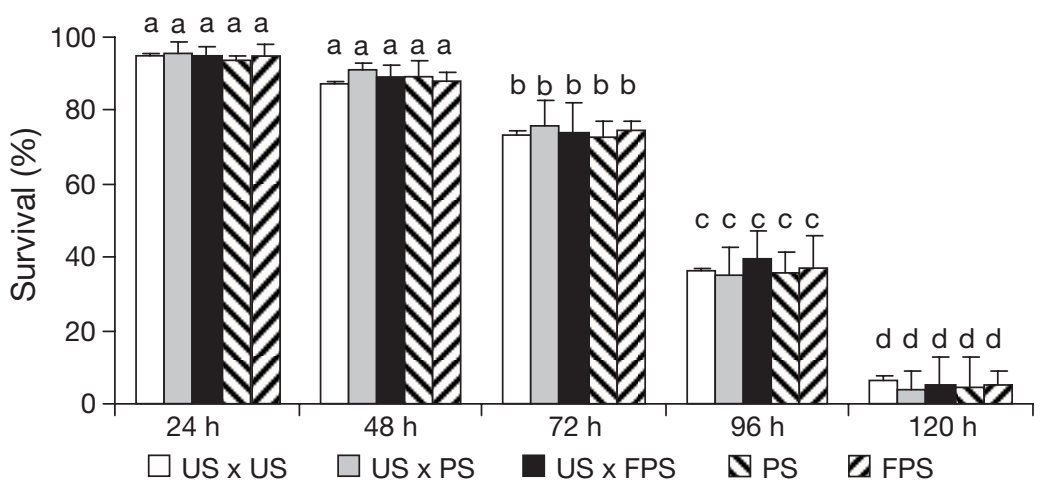

Fig. 2. Lysmata amboinensis. Mean survival ( $\pm \mathrm{SD})$ of larvae starved for 24, 48, 72,96 and $120 \mathrm{~h}$ and produced by shrimp parasitized with bopyrid isopods (PS) shrimp formerly parasitized (FPS) and unparasitized shrimp (US) paired with US, PS and FPS. Different superscript letters represent significant differences $(\mathrm{p}<0.05) ; \mathrm{n}=210$ larvae per treatment

ously hermaphroditic shrimp Lysmata amboinensis, but does not cause its castration. This result differs from that recorded by Calado et al. (2005) for the simultaneously hermaphroditic shrimp Lysmata seticaudata parasitized by the bopyrid isopod Eophryxus lysmatae (an abdominal parasite). In the latter case, the abdominal bopyrid isopod caused the castration of the female function of its host. Similar results were also recorded in the preliminary works of Fiedler (2000) who observed that Lysmata anchisteus Chace 1972, L. ternatensis De Man, 1902 and L. trisetacea (Heller, 1861) were parasitized by undescribed bopyrid isopods that occupied the abdomen of their hosts. Despite being parasitized by branchial or abdominal bopyrid isopods, simultaneously hermaphroditic shrimp of the genus Lysmata always retain a fully functional male sexual system, preventing full 'reproductive death' of the host. Among gonochoric species, the feminization of male pleopods induced by bopyrids prevents them from successfully copulating (Reinhard 1956). However, the pleopods of Lysmata spp. are feminized during their transition from male to the simultaneously hermaphroditic phase while retaining the ability to successfully fertilize oocytes (Fiedler 1998). Additional evidence of this ability was provided by Zhang \& Lin (2004), who demonstrated that specimens with ablated anterior pleopods were able to successfully fertilize oocytes.

The reduction in female reproductive function of PS by the bopyrid isopod does not seem to affect larval quality: starvation tests showed that larval survival did not differ significantly among US, PS and FPS. Additionally, larvae produced by US and fertilized by PS displayed a similar quality to those produced by US and fertilized by other US. Therefore, we may assume that host embryo production is only quantitatively, not qualitatively, effected.

Despite the release of bopyrid larvae by adult parasites, the absence of newly infected shrimp during the experimental period can be explained by the use of artificial seawater that lacked calanoid copepods, which act as intermediate hosts (Dale \& Anderson 1982).

Although bopyrids that infect the branchial chamber seem to be well adapted against being dislodged during the molt of their host (Cash \& Bauer 1993), parasitized shrimp may still lose their parasite during ecdysis and reassume their 'normal' reproductive performance as shown in the present study. These results suggest that the only permanent impact caused by the parasite to its host is the deformation of the cephalothorax. Since host and parasite endocrinology is still insufficiently known, energy drain and/or endocrine disruption have been suggested to be the mechanism responsible for the occurrence of parasitic castration. Increased nutritional demand by the parasite significantly affects PS energy flow as a result of consumption of host hemolymph and nutrient imbalance (Rein- 
hard 1956, Anderson 1977, Walker 1977), and may be enough to impair the production of energetically costly vitellogenic oocytes. With regards to endocrine disruption, parasites may deplete titers of reproductive hormones, stimulate the production of the gonad-inhibiting hormone (GIH) or even secrete GIH (Baudoin 1975, Walker 1977, Beck 1980).

The different degrees of inhibition of the female function owing to bopyrid isopods (total in the case of abdominal parasites and partial in that of branchial parasites) currently detected in the genus Lysmata may be accounted for by the relative larger size of abdominal parasites, which may drain more energy or disrupt endocrine mechanisms more severely than branchial bopyrids. Nevertheless, branchial parasites (whose biomass only accounts for $4 \%$ of the host-parasite system) are known to significantly affect host energetics (Anderson 1977). Another possible explanation is the simple physical obstruction that abdominal parasites may present to the migration of newly extruded eggs and their attachment to host pleopods.

Although US readily mated with PS under the laboratory conditions of the present study, and although PS fertilized eggs as successfully as US, it could be possible that US prefer other US over PS as mating partners in their natural environment. Game-theory models based on the Prisoner's Dilemma (Rapoport \& Chammah 1965) and the Hermaphrodite's Dilemma (Leonard 1990) predict that 2 simultaneous hermaphrodites cooperate via reciprocal gender swapping. However, Webster et al. (2003) demonstrated the existence of selective mating behavior in the simultaneously hermaphroditic freshwater snail Biomphalaria glabrata (Say, 1818): unparasitized snails refused to copulate as females with an infected partner.

Future studies should address the reproductive success of PS when competing for copulation with US and, as suggested by Fiedler (2000), evaluate the evolutionary role that parasitic castration might have had in the unique mating system of the genus Lysmata.

Acknowledgements. We thank Fundação para a Ciência e a Tecnologia (scholarship SFRH/BPD/18009/2004) from the Portuguese government for their financial support. We also express our gratitude to S. Dantas and L. Simões from the Templo Aquático team for their technical support.

\section{LITERATURE CITED}

Anderson G (1977) The effects of parasitism on energy flow through laboratory shrimp populations. Mar Biol 42: 239-251

Editorial responsibility: Timothy Flegel,

Bangkok, Thailand
Anderson G (1990) Postinfection mortality of Palaemonetes spp. (Decapoda: Palaemonidae) following experimental exposure to the bopyrid isopod Probopyrus pandalicola (Packard) (Isopoda: Epicaridea). J Crustac Biol 10:284-292

Baudoin M (1975) Host castration as a parasitic strategy. Evolution 29:335-352

Bauer RT (2000) Simultaneous hermaphroditism in caridean shrimps: a unique and puzzling sexual system in the Decapoda. J Crustac Biol 20:116-128

Beck JT (1980) The effect of an isopod castrator, Probopyrus pandalicola, on the sex characters of one of its caridean shrimp hosts, Palaemonetes paludosus. Biol Bull (Woods Hole) 158:1-15

Calado R, Bartilotti C, Narciso L (2005) Short report on the effect of a parasitic isopod on the reproductive performance of a shrimp. J Exp Mar Biol Ecol 321:13-18

Cash CE, Bauer RT (1993) Adaptations of the branchia ectoparasite Probopyrus pandalicola (Isopoda: Bopyridae) for survival and reproduction related to ecdysis of the host, Palaemonetes pugio (Caridea: Palaemonidae). J Crustac Biol 13:111-124

Dale WE, Anderson G (1982) Comparison of morphologies of Probopyrus bithynis, $P$. floridensis, and $P$. pandalicola larvae reared in culture (Isopoda, Epicaridea). J Crust Biol 2: 392-409

Fiedler GC (1998) Functional, simultaneous hermaphroditism in female-phase Lysmata amboinensis (Decapoda: Hippolytidae). Pac Sci 52:161-169

Fiedler GC (2000) Sex determination and reproductive biology of two caridean shrimp genera: Hymenocera and Lysmata. PhD dissertation, University of Hawaii

Leonard JL (1990) The hermaphrodite's dilemma. J Theor Biol 147:361-372

Markham JC (1986) Evolution and zoogeography of the Isopoda Bopyridae, parasites of Crustacea Decapoda. In: Gore RH, Heck KL (eds) Crustacean issues 4: Crustacean biogeography. A. A. Balkema, Rotterdam, p 143-164

O'Brien J, Van Wyk PM (1985) Effects of crustacean parasitic castrators (epicaridean isopods and rizocephalan barnacles) on growth of crustacean hosts. In: Wenner AM (ed) Crustacean issues 3: Factors in adult growth. A. A. Balkema, Rotterdam, p 191-218

Rapoport A, Chammah AM (1965) Prisoner's dilemma: a study in conflict and cooperation. University of Michigan Press, Ann Arbor, MI

Reinhard EG (1956) Parasitic castration of Crustacea. Exp Parasitol 5:79-107

Van Wyk PM (1982) Inhibition of the growth and reproduction of the porcellanid crab Pachycheles rudis by the bopyrid isopod, Aporobopyrus muguensis. Parasitology 85: 459-473

Walker SP (1977) Probopyrus pandalicola: discontinuous ingestion of shrimp hemolymph. Exp Parasitol 41:198-205

Webster JP, Hoffman JI, Berdoy M (2003) Parasite infection, host resistance and mate choice: battle of the genders in a simultaneous hermaphrodite. Proc R Soc Lond B 270: 1481-1485

Zar JH (1996) Biostatistical analysis. Prentice Hall, Upper Saddle River, NJ

Zhang D, Lin J (2004) Fertilization success without anterior pleopods in Lysmata wurdemanni (Decapoda: Caridea), aprotandric simultaneous hermaphrodite. J Crustac Biol $24: 470-473$

Submitted: March 15, 2006; Accepted: July 20, 2006

Proofs received from author(s): October 29, 2006 